\title{
Family planning providers' perspectives on family planning service delivery in Ibadan and Kaduna, Nigeria: a qualitative study
}

\author{
Luciana Estelle Hebert, ${ }^{1}$ Hilary Megan Schwandt, ${ }^{2}$ Marc Boulay, ${ }^{3}$ \\ Joanna Skinner ${ }^{4}$
}

\begin{abstract}
'Doctoral Student, Department of Population, Family and Reproductive Health, Johns Hopkins Bloomberg School of Public Health, Baltimore, MD, USA

${ }^{2}$ Technical Advisor, Center for Communication Programs, Johns Hopkins Bloomberg School of Public Health, Baltimore, MD, USA

${ }^{3}$ Assistant Professor and Senior Program Evaluation Officer, Center for Communication Programs, Johns Hopkins Bloomberg School of Public Health, Baltimore, MD, USA ${ }^{4}$ Monitoring and Evaluation Advisor, Center for Communication Programs, Johns Hopkins Bloomberg School of Public Health, Baltimore, MD, USA
\end{abstract}

\section{Correspondence to}

Ms Luciana Estelle Hebert, Department of Population, Family and Reproductive Health, Johns Hopkins Bloomberg School of Public Health, Baltimore, MD 21205, USA; Ihebert@jhsph.edu

Received 27 October 2011 Revised 26 February 2012 Accepted 23 April 2012 Published Online First 20 August 2012
To cite: Hebert $L E$, Schwandt HM, Boulay M, et al. Journal of Family Planning and Reproductive Health Care 2013, 39 29-35.

\section{ABSTRACT}

Objective In Nigeria, fertility continues to be high and contraceptive prevalence remains low. This study was conducted in order to understand the perceptions of, experiences with and challenges of delivering family planning services in two urban areas of Nigeria from the perspectives of family planning service providers. Methods A qualitative study using 59 in-depth interviews was conducted among family planning providers working in hospitals, primary health centres, clinics, pharmacies and patent medicine vendors in Ibadan and Kaduna, Nigeria. Results Providers support a mix of individuals and organisations involved in family planning provision, including the government of Nigeria. The Nigerian government's role can take a variety of forms, including providing promotional materials for family planning facilities as well as facilitating training and educational opportunities for providers, since many providers lack basic training in family planning provision. Providers often describe their motivation to provide in terms of the health benefits offered by family planning methods. Few providers engage in any marketing of their services and many providers exclude youth and unmarried individuals from their services.

\section{Conclusions The family planning provider} community supports a diverse network of providers, but needs further training and support in order to improve the quality of care and market their services. Adolescents, unmarried individuals and women seeking post-abortion care are vulnerable populations that providers need to be better educated about and trained in how to serve. The perspectives of providers should be considered when designing family planning interventions in urban areas of Nigeria.

\section{INTRODUCTION}

The connection between family planning service quality and contraceptive use at the

\section{Key message points}

- Some groups such as adolescents and unmarried individuals are routinely excluded from family planning services.

- Family planning providers need more marketing materials in order to promote family planning.

- Family planning providers of all cadres need training to empower them to be able to better respond to and counsel clients about different family planning methods.

population level is generally acknowledged as exhibiting a positive association. ${ }^{1}$ In Nigeria, where contraceptive prevalence remains at a low 10\% among married women and $20 \%$ of women have an unmet need for contraception, ${ }^{2}$ understanding the roles and perspectives of family planning providers is a critical step in designing effective interventions to both stimulate demand and increase usage of contraceptive methods.

Family planning providers in Nigeria span a wide range of facilities, professions and skill levels. The private sector encompasses all patent medicine vendors (PMVs) and pharmacies, while all primary health centres (PHCs) are publicly funded by the government; hospitals and clinics can be either public or private entities. PMVs, which comprise at least half of the family planning providers, are for-profit entities that sell drugs but whose proprietors are not required to be trained in drug dispensing. ${ }^{3} 4$ Pharmacies are usually staffed by a licensed pharmacist and function primarily as a source for prescribing and dispensing drugs; clinics, hospitals and PHCs are staffed by trained medical professionals and are responsible for seeing and treating patients. ${ }^{3}$ 
The selection of methods offered varies by provider. While PMVs are expected to stock contraceptives such as condoms, ${ }^{5}$ they are allowed only to re-supply, but not initiate, oral contraceptive pills. ${ }^{6}$ They are also prohibited from providing injectable contraceptive and emergency contraception services, though some do so regardless. ${ }^{7}$ Hospitals tend to offer a greater number of contraceptive methods, with a mean number of 3.9 methods offered. ${ }^{3}$ Despite a more limited selection of methods, $60 \%$ of Nigerian women using a modern method receive their method at private facilities, such as PMVs and pharmacies. ${ }^{2}$ The three most frequently used methods in Nigeria are the male condom $(4.7 \%)$, the injectable $(2 \%)$ and the pill $(1.6 \%) .{ }^{2}$ While condoms and pills are the most widely offered methods among all providers, the injectable is usually obtained only from hospitals and health centres.

Previous research in Nigeria has mostly centred around specific cadres of family planning providers, for example PMVs or physicians serving in primary care settings. ${ }^{6} 89$ A fair amount of this research has focused on knowledge, attitudes and practice regarding particular methods, specifically emergency contraception and abortion. ${ }^{6-11}$ Less research has focused on family planning provision itself. Given the prominence of private sector providers, segregated inquiry into provider perspectives by facility type leads to a limited understanding of family planning service delivery in Nigeria. Moreover, since many providers offer some mix of methods (albeit less than optimum), focusing on just one method illustrates only part of the picture regarding service provision.

Both within and outside Nigeria, provider perspectives are known to impact family planning provision. Within Nigeria, providers' views and concerns regarding adolescent sexuality are associated with the contraceptive services they are willing to provide to adolescents. ${ }^{12}$ Situation analyses performed at clinically-based family planning service delivery points in Nigeria show that provider-imposed eligibility restrictions (based on age, parity or spousal consent) exist among many providers for specific methods. ${ }^{13}$ In Ghana, providers' own personal beliefs or biases are reflected in the services they provide or restrict to clients. ${ }^{14}$ In Uganda, providers face various barriers and challenges related to method availability and supply, providers' own knowledge levels and financial accessibility, influencing the quality of care they are able to provide. ${ }^{15}$

Incorporating research on providers is thus an integral component in understanding the family planning context within a country. Recognition of how various providers envision the role of the government can help clarify areas wherein the government can support the existing provider network and opportunities to empower individual providers to improve their own services. Consideration of why providers choose to deliver family planning can help describe providers' goals in counselling and dealing with clients. Evaluating the current marketing strategies of facilities can help explain client flow and demand in providers' communities. Understanding the limits to care imposed by the providers themselves can illustrate why certain methods are less utilised than others and why certain groups continue to be underserved by the current family planning care network.

The Nigerian Urban Reproductive Health Initiative (NURHI) set out to understand the perceptions of and experiences with family planning service provision in two urban areas of Nigeria from the perspectives of family planning service providers from all facility types. The purpose of this exercise was to inform programmes designed to improve family planning services across urban Nigeria, since nearly half of the population currently resides in urban areas. ${ }^{16}$ Using a sample of facilities that was elicited by community members, this study first explores how providers describe their perceptions of, experience with and challenges to delivering family planning in urban areas of Nigeria. It then reflects on how the perspective of providers can be used to inform programmes aiming to improve urban family planning provision.

\section{METHODS}

Qualitative methods, specifically in-depth interviews using a structured guide, were used to collect these data. Interviewers also used an observation checklist in order to evaluate family planning marketing inside the facility, outside the facility, on the facility walls, as well as the specific content and target audience for the promotional family planning materials.

A total of 59 in-depth interviews were conducted in September and October 2010 among male and female family planning providers in facilities in Ibadan and Kaduna, Nigeria. In each urban area interviews were conducted in a slum neighbourhood, a low-income neighbourhood and a middle-income neighbourhood. Communities that comprised each income level were selected through consultation with the Ministry of Health and academic demographers. Family planning providers were recruited based upon identification of the facility as providing family planning during a corresponding community mapping exercise with male and female community members. In order to encompass the varied types of facilities providing family planning in Nigeria, the project sought to include a combination of up to 10 facilities located in each of the six areas. While an array of types of facilities was desired, recruitment was contingent upon those identified in the mapping exercise. The final sample of providers is listed in Table 1.

Ethical approval to conduct the study was obtained from the Institutional Review Board at the Johns Hopkins Bloomberg School of Public Health in Baltimore, MD, USA and the Obafemi Awolowo University, Ile-Ife, Nigeria. Additional approvals were 
Table 1 Characteristics of sampled family planning facilities by facility type, public or private status and community income level in Ibadan and Kaduna, Nigeria

\begin{tabular}{lcccccc}
\hline Family planning facility & Private & Public & Slum & Lower income & Middle income & Total \\
\hline Clinic & 10 & 1 & 4 & 3 & 4 & 11 \\
Hospital & 3 & 1 & 1 & 2 & 1 & 4 \\
Primary health centre & 0 & 8 & 2 & 3 & 3 & 8 \\
Pharmacy & 12 & 0 & 2 & 6 & 8 & 12 \\
Patent medicine vendor & 24 & 0 & 10 & 6 & 20 & 24 \\
Total & 49 & 10 & 19 & 20 & & 59 \\
\hline
\end{tabular}

obtained from the state Ministry of Health in the two states where the study was conducted. Qualified and experienced research assistants were recruited and trained by the research firm hired to collect the data. The in-depth interview guides were pretested with urban providers during the training and were refined based on the pretest results. After study recruitment, verbal informed consent was obtained from all study participants before proceeding.

All interviews, with the consent of the participants, were audio-taped and the recordings were transcribed verbatim in the local languages. The transcribed texts were then translated into English. Data sorting and analysis were carried out using ATLAS.ti ${ }^{\mathrm{TM}}$ software and interview level matrices in Microsoft Excel $^{\mathrm{TM}}$. In addition to using the interview guide to develop the analysis codes, all transcripts were read to identify emerging themes and allow for the generation of new codes based upon the providers' own words. In this study 'coding up' as opposed to 'coding down' was utilised; meaning that the codes were developed based on the data and were not defined prior to data collection. ${ }^{17}$ The data analysis was guided by the thematic content analysis approach. ${ }^{18}$

\section{RESULTS}

\section{Who should provide family planning}

Providers named a wide variety of entities that they believed should be charged with either the ability or responsibility of delivering family planning to Nigerians, with support for a combination of providers, spanning all facility types.

\section{"I think everybody should be involved in providing family planning. Every shop should be actively involved - not only pharmacies and private medical vendors. Family planning need is just as the need for sanitary pad." [Female, proprietor, pharmacy, slum, Ibadan]}

While some reserved provision of family planning for "qualified" providers only, others described delivery points needing to be "close to the people". Some also expressed support for community-level providers for easy to administer methods, but reserved distribution of other methods for skilled care settings.
The Nigerian government's role in family planning

While providers expressed support for an integrated network of providers involved in the delivery of family planning, they also voiced support for the government playing a strong role in family planning services. Because the government has greater resources, some charged it with an instrumental role in the provision of family planning, through either direct or subsidised distribution of methods. Others envisioned a broader role for the government, in either empowering community level providers or by educating the populace in order to stimulate demand and foster a more demand-driven environment for family planning efforts.

"It [family planning] should be the responsibility of every one of us that is, the Government, concerned people and non-governmental organisations. Nonetheless, when it comes to education and enlightenment on family planning services, I think the Government should take the lead." [Female, PHC, middle income, Kaduna]

Providers also voiced support for government promotion of family planning, expressing the need for promotional materials in order to market both their own specific services but also to promote family planning in general. Providers saw this as an opportunity for the government to create and distribute materials for these purposes. Finally, providers expressed how government support of health facilities, through a variety of forms including supply assurance and training, would better enable them to deliver family planning services.

\begin{abstract}
"There should be governmental institutional support for private individuals that offer family planning. It could be in terms of consistent supply of family planning methods and funds for organising community-based programmes on family planning." [Male, pharmacist in charge, pharmacy, middle income, Kaduna]
\end{abstract}

\section{Staff training and counselling}

In general, most providers had not received any training in family planning.

"None of our staff has received formal training on family planning services. Nevertheless, they all provide the services." [Female, manager, pharmacy, middle income, Ibadan] 
Training on family planning was more common among those in hospitals, PHCs and clinics, although there was often a mix of trained and untrained staff members. As a safeguard to this, a system of internal referral to more skilled or knowledgeable providers was sometimes used by providers, so that questions requiring more knowledge or administration of more complex methods could be addressed properly. Among pharmacists and PMVs, many saw no problem with staff having no training, describing condoms and pills as easy to administer and requiring only "on the job" training.

"...they were not trained in providing family planning services but because they sell the methods on a daily basis I think that's enough to give them experience to counsel people." [Male, manager, pharmacy, slum, Ibadan]

\section{Motivation to provide family planning}

Some providers explained they were motivated to offer family planning because of the health benefits associated with family planning use. Providers framed these reasons primarily in terms of the health of the mother and the child. Some described how family planning enabled women to space and limit their births and some mentioned safe motherhood and reduction of mortality (especially due to unsafe abortion) as opportunities made possible by family planning. Providers at hospitals, PHCs and clinics cited health reasons as motivations to offer family planning more often than providers at PMVs and pharmacies.

\footnotetext{
"The reason why we began to offer family planning in this hospital was because health is wealth. Some women believe that since they are married their husbands have every right to demand sex at will. Most of the time, the outcome is an unwanted pregnancy. We encourage women to take their health as priority during the childbearing period through effective application of family planning mechanisms. We strongly believe that the use of family planning will minimise some of the pregnancy-related complications." [Female, chief nursing officer, PHC, low income, Ibadan]
}

A number of providers also explained that their decision to offer family planning was in response to the demand for the service from their clients. This reason was more commonly mentioned among providers at pharmacies and PMVs than among other health care providers. Even among those providers where initial demand motivated them to begin selling, some also mentioned the collateral benefits offered with family planning, including those relating to health:

\footnotetext{
"What encouraged me initially was high demand [for family planning] received from the people. But now I think profit is not my major driver but how to improve the reproductive health outcomes of every individual
}

by offering them what they can use to achieve this."

[Female, owner, PMV, slum, Kaduna]

Nearly all providers planned to continue delivery of family planning and many described a strong commitment to their customers and to the goals of family planning as reasons why they planned to continue. In fact, most providers said that they would like to expand their family planning services, either in amount or range of methods offered; however, some reasoned that an increase in demand, both in general and in terms of specific methods, would be needed in order to expand family planning services.

\section{Marketing of family planning services}

While many providers understand the potential role that promotion of family planning can play in expanding contraceptive usage among their clients as well as throughout the country, few actually engage in any real promotional activities. Most providers shied away from any external promotion of their services and products, relying instead on in-house marketing, using posters or stickers to promote products inside the facility. Many providers also mentioned counselling clients on family planning as a way of letting clients know they offer family planning, and relying on word-of-mouth facilitated by this counselling.

"The people that patronise the facility tell each other about the family planning services offered here.... There is no provision to inform the people who are not using the facility about the family planning services offered here." [Male, director, private clinic, slum, Ibadan]

A substantial number of providers used in situ advertising of family planning methods, relying simply on the product alone to promote itself on the shelf.

"Both users and non-users know that I offer family planning services because it is openly displayed on the shelf." [Male, owner, pharmacy, middle income, Kaduna]

Whether this lack of formal marketing techniques stemmed from lack of will or lack of materials was unclear, though few facilities had any external signage advertising family planning services.

\section{Excluded clients}

Providers often purposely excluded youth and unmarried individuals from their family planning services. While most did not provide justification for withholding family planning from these groups, concerns about promiscuity were mentioned.

"I don't like attending to youth because of their involvement in what they are not due for. Also, I don't like attending to the unmarried people." [Female, owner, PMV, slum, Ibadan] 
Some providers offered that youth should instead seek services from "youth-friendly centres". This pattern of exclusion of youth and unmarried tended to be more common among pharmacies and PMVs than among clinics, hospitals and PHCs, but was still unsettlingly prevalent across provider type.

\section{Post-abortion care}

Across facilities, many providers said they refer women seeking post-abortion care (PAC) to facilities equipped to help PAC patients, usually government hospitals or other "appropriate health centres". When able, providers mentioned advising these women to use family planning to prevent unwanted pregnancies from the offset. Some providers also mentioned the sensitive nature of providing PAC, since induced abortion is illegal in Nigeria.

\begin{abstract}
"We don't deal with post-abortion care because it could be implicating and you may be jailed if the person dies in the process. We usually refer them to the appropriate hospitals where they can be treated." [Male, manager, PMV, slum, Kaduna]
\end{abstract}

Alarmingly, a couple of primary health centres discussed treating only patients who had experienced spontaneous abortion, claiming to refuse care to those among whom the abortion was induced.

\section{"We do on few occasions especially when there are complications due to natural pregnancy termination, but not induced abortions. We don't treat such cases here and we don't abort." [Female, nursing officer, PHC, low income, Ibadan]}

In addition, some providers described sending women seeking PAC back to the providers from whom they received the abortion, rather than to a health facility equipped to handle the case.

"We treat those with post-abortion complications especially spontaneous abortion. If it is induced, we refer them to where the abortion was conducted." [Female, community health extension worker, PHC, low income, Kaduna]

\section{DISCUSSION}

The provider's perspective in family planning delivery represents an important component in effective provision and usage of family planning. ${ }^{19} 20$ To date, no known qualitative research has elicited the perspectives of all variants of family planning providers in Nigeria in one study; thus, this study is the first to do so. Though conducted in just Kaduna and Ibadan, the findings from this study can provide insight into how family planning service delivery can be improved throughout urban areas of Nigeria.

Providers support a diverse network of providers, reflecting the varying skill and care levels already providing services to users throughout Nigeria. ${ }^{21}$ Of note, however, is the insight that providers themselves express the need for a variety of providers based on the level of training or knowledge needed to administer a method. Additionally, since a number of providers already use an informal system of internal referral, this demonstrates that those providing family planning are cognisant of the limits of their skills, and thus the limits of their services. Despite these safeguards, however, the low prevalence of training in family planning methods, both within and outside skilled care settings, points to a clear area for improvement. This lack of training in family planning has been seen in previous research among PMVs in Nigeria. ${ }^{6}$ Since the role of counselling is generally regarded as integral in contraceptive uptake and use, training providers in all spheres of skill should be prioritised. $^{22-24}$

At present, the federal government's policystipulated role in family planning delivery includes procurement and distribution of methods, training of health professionals and mass media communication programmes, in collaboration with non-governmental organisations (NGOs) and aid agencies such as the United Nations Population Fund (UNFPA) and the Department for International Development (DFID). ${ }^{25}$ However, these policy goals apply primarily to government-operated facilities, such as PHCs, and thus exclude the private sector. Given the needs of providers, as well as their support for government involvement in family planning, these data provide evidence of the potential acceptability for a greater role for the Nigerian Ministry of Health in supporting individual, including private, providers. Providers' approval of the current mix of provision through pharmacies, PMVs, clinics, PHCs and hospitals indicates that family planning services should continue to be provided from a variety of service points; beyond simply policy enactment that sets targets for increasing contraceptive prevalence, ${ }^{26}$ it appears from these data that instrumental government support through promotional materials, educational opportunities and training would be acceptable to providers at the community level. In addition to greater government involvement, connecting providers to NGOs and other family planning groups can further strengthen the ability of providers to deliver quality family planning care. Working with providers to evaluate the optimal modes of support might best serve Nigerians while also preserving the business and livelihoods of providers working in the private sector. Providers' call for more government support is especially compelling given the dominance of private facilities in the family planning market in Nigeria.

Since most providers interviewed were aware of the health benefits that come with family planning, and many espoused these benefits as well as the desire to meet demand and serve their clients as reasons they choose to provide, tapping into this duty-based reasoning could be an opportunity to educate and train 
providers. Furthermore, many providers do not have the means or materials to promote their services in their community, thus distribution of materials supporting and promoting family planning would likely be well received in the provider community. While exposure to mass media messages is positively associated with contraceptive use, ${ }^{24} 27$ and there have been family planning logo distribution campaigns in the past, ${ }^{3}$ providers in this sample lack the materials needed to promote their own services. Thus, this area represents an opportunity for the Nigerian government and NGOs to better equip providers to market and promote the family planning services they provide.

Providers in this sample also exhibited exclusionary practices based on age or marital status, as has been documented elsewhere in Nigeria and sub-Saharan Africa. ${ }^{12}{ }^{14}$ Research using mystery clients has shown that adolescents experience negative and judgmental attitudes and are sometimes counselled in religious matters rather than contraceptive methods when trying to access family planning services. ${ }^{28}$ Whereas prior studies have indicated that youth prefer to use PMVs for family planning because they perceive these providers to be easy to access and confidential, ${ }^{29}$ the present data indicate that providers' own exclusionary preferences may further prevent young and unmarried Nigerians from accessing reproductive and sexual health services. In these data, PMVs and pharmacists tended to exclude young and unmarried clients more often than did those working in clinics, hospitals and PHCs. Future efforts should, therefore, attempt to increase providers' knowledge of the consequences of these exclusionary practices. Interventions could possibly explore incentive systems in order to motivate providers to include youth and unmarried in their services, as has been found to be successful in other contexts. ${ }^{30}$

Improvements also remain to be made in the realm of PAC. While most providers reported referring women seeking PAC to "appropriate" facilities, this was not universal nor was there any verification of whether those particular facilities were indeed capable of treating PAC clients. Efforts should be made to increase transparency and publicity around facilities that offer PAC, especially within the provider community. Previous research has shown inadequate awareness of PAC services among providers; as those findings are echoed in these data, it would serve Nigerian women well if the provider community were informed of the appropriate facilities and procedures to make referrals for PAC. ${ }^{31}$

Since some of these recommended improvements would likely require a cultural shift in order to truly be effective, a number of strategies could help bridge this cultural gap. Reaching out first to leaders in the family planning service community to serve as change agents could channel resources and skills into high- impact individuals. Focusing on these individuals first could lead to delivery of culturally sensitive promotion of improvements in family planning, while also being responsive to the concerns that some providers hold. Furthermore, identification of these leaders can better promote the development of a well-functioning family planning provider network, which Nigeria currently lacks.

The perspectives of family planning providers in urban areas in Nigeria should be incorporated into any strategies attempting to improve contraceptive services delivery and provide quality family planning care to Nigerians. These data indicate clear areas for improving the family planning landscape in urban areas of Nigeria and are already being used to inform NURHI family planning programme activities in the areas of demand generation, health systems strengthening, developing and supporting a family planning provider network and advocacy. Through utilisation of the current network of family planning providers, offering greater educational and training opportunities in family planning can address both lack of knowledge and combat the personal biases of many providers. In addition, the government and NGOs can play a more active role in supporting family planning providers by offering training opportunities as well as distributing materials to enable providers to market their services and promote family planning in general. Lastly, efforts should be made to foster a more integrated and knowledgeable referral network for PAC services, through network building and information-sharing. Strengthening the provider community through these mechanisms has the potential to increase not only the availability but also the quality of family planning delivery in Nigeria.

Acknowledgements This study was made possible by the generous support of the Bill and Melinda Gates Foundation. The contents are the responsibility of the Nigerian Urban Reproductive Health Initiative (NURHI) and do not necessarily reflect the views of the Bill and Melinda Gates Foundation. The research was made possible by the leadership and staff of the NURHI project: Dr Mojisola Odeku (Director), Bola Kusemiju (Deputy Director) and the entire NURHI team. The authors wish to thank their research partner in Nigeria, Population Reproductive Health Program (PRHP) of Gates Institute, Obafemi Awolowo University in Ile-Ife, and the family planning providers who consented to be interviewed for this study.

Funding Funding for this study was provided by the Bill and Melinda Gates Foundation.

Competing interests None.

Provenance and peer review Not commissioned; externally peer reviewed. 


\section{REFERENCES}

1 Jain AK. Fertility reduction and the quality of family planning services. Stud Fam Plann 1989;20:1-16.

2 Nigerian Demographic and Health Survey 2008 Final Report. Abuja, Nigeria: National Population Commission, Federal Republic of Nigeria, and Calverton, MD: ICF Macro, 2009.

3 Gao J, Chapman S, Sun S, et al. The growth in newspaper coverage of tobacco control in China, 2000-2010. BMC Public Health 2012;12:160.

4 Oshiname FO, Brieger WR. Primary care training for patent medicine vendors in rural Nigeria. Soc Sci Med 1992;35:1477-1484.

5 Ministry of Health, Federal Republic of Nigeria. Essential Drugs List - Fourth Revision 2003. Abuja, Nigeria: Federal Ministry of Health, 2003.

6 Fayemi MM, Oduola OL, Ogbuji QC, et al. The knowledge of emergency contraception and dispensing practices of patent medicine vendors in South West Nigeria. J Public Health Policy 2010;31:281-294.

7 Okonkwo AD, Okonkwo UP. Patent medicine vendors, community pharmacists and STI management in Abuja, Nigeria. Afr Health Sci 2010;10:253-265.

8 Brieger WR, Osamor PE, Salami KK, et al. Interactions between patent medicine vendors and customers in urban and rural Nigeria. Health Policy Plan 2004;19:177-182.

9 Okonofua FE, Shittu SO, Oronsaye F, et al. Attitudes and practices of private medical providers towards family planning and abortion services in Nigeria. Acta Obstet Gynecol Scand $2005 ; 84: 270-280$.

10 Onah HE, Ogbuokiri CM, Obi SN, et al. Knowledge, attitude and practice of private medical practitioners towards abortion and post abortion care in Enugu, South-eastern Nigeria. J Obstet Gynaecol 2009;29:415-418.

11 Ebuehi OM, Ebuehi OA, Inem V. Health care providers' knowledge of, attitudes toward and provision of emergency contraceptives in Lagos, Nigeria. Int Fam Plan Perspect 2006;32:89-93.

12 Adekunle AO, Arowojolu AO, Adedimeji AA, et al. Adolescent contraception: survey of attitudes and practice of health professionals. Afr J Med Med Sci 2000;29:247-252.

13 Askew I, Mensch B, Adewuyi A. Indicators for measuring the quality of family planning services in Nigeria. Stud Fam Plann 1994;25:268-283.

14 Stanback J, Twum-Baah KA. Why do family planning providers restrict access to services? An examination in Ghana. Int Fam Plan Perspect 2001;27:37-41.

15 Mugisha JF, Reynolds H. Provider perspectives on barriers to family planning quality in Uganda: a qualitative study. J Fam Plann Reprod Health Care 2008;34:37-41.

16 United Nations. World Urbanization Prospects, the 2009 Revision: Highlights. New York, NY: United Nations, Department of Economic and Social Affairs, Population Division, 2010.
17 Forrest Keenan K, van Teijlingen E, Pitchforth E. The analysis of qualitative research data in family planning and reproductive health care. J Fam Plann Reprod Health Care 2005;31:40-43.

18 Green JA, Cyster JG. S1PR2 links germinal center confinement and growth regulation. Immunol Rev 2012;247:36-51.

19 Paine K, Thorogood M, Wellings K. The impact of the quality of family planning services on safe and effective contraceptive use: a systematic literature review. Hum Fertil (Camb) 2000;3: 186-193.

20 Shelton JD. The provider perspective: human after all. Int Fam Plan Perspect 2001;27:152-161.

21 Oye-Adeniran BA, Adewole IF, Umoh AV, et al. Sources of contraceptive commodities for users in Nigeria. PLoS Med 2005;2:e306.

22 Gallen M, Lettenmaier C, Green C. Counseling Makes a Difference. Population Reports, Series J, No. 35. Baltimore, MD: Population Information Program, The Johns Hopkins University, 1987.

23 Rudy SJ, Polomano R, Murray WB, et al. Team management training using crisis resource management results in perceived benefits by healthcare workers. J Contin Educ Nurs 2007;38:219-226.

24 RamaRao S, Mohanam R. The quality of family planning programs: concepts, measurements, interventions, and effects. Stud Fam Plann 2003;34:227-248.

25 Ministry of Health, Federal Republic of Nigeria. National Reproductive Health Policy and Strategy to Achieve Quality Reproductive and Sexual Health for All Nigerians. Abuja, Nigeria: Federal Ministry of Health, 2001.

26 Federal Government of Nigeria. National Policy on Population for Sustainable Development. Abuja, Nigeria: Federal Government of Nigeria, 2004.

27 Bankole A, Rodríguez G, Westoff CF. Mass media messages and reproductive behaviour in Nigeria. J Biosoc Sci 1996;28:227-239.

28 Olowu F. Quality and costs of family planning as elicited by an adolescent mystery client trial in Nigeria. Afr J Reprod Health 1998;2:49-60.

29 Otoide VO, Oronsaye F, Okonofua FE. Why Nigerian adolescents seek abortion rather than contraception: evidence from focus-group discussions. Int Fam Plan Perspect 2001;27:77-81.

30 Meuwissen LE, Gorter AC, Kester AD, et al. Can a comprehensive voucher programme prompt changes in doctors' knowledge, attitudes and practices related to sexual and reproductive health care for adolescents? A case study from Latin America. Trop Med Int Health 2006;11:889-898.

31 Adinma JI, Ikeako L, Adinma ED, et al. Awareness and practice of post abortion care services among health care professionals in southeastern Nigeria. Southeast Asian J Trop Med Public Health 2010;41:696-704.

\section{Access to Online First Journal Articles, Blogs and Podcasts via the Faculty Website}

Faculty members can easily access journal articles that have been recently published online via the Online First facility at http://www.fsrh.org/pages/the_journal.asp before they appear in a print issue of the Journal. They can also access the latest blogs and online podcasts from this link. 